\title{
Discrimination of Roma Women Regarding Their Access to Reproductive Health Services in
} Albania

\author{
Dr Nadia Rusi \\ University of Tirana, Faculty of Law
}

\begin{abstract}
The situation of Roma women regarding the provision of the reproductive health services is a sensitive issue in the Albanian reality, in the framework of the implementation of the fundamental rights and in the framework of achieving social justice. Previous reports with their focus on "Roma population" have brought surveys related to different fields, including employment, education and estimation of the general situation of Roma community in such fields. From this point of view it is estimated that there is a lack of special reports treating only the situation of Roma women, in different aspects of their economic, social, cultural life and their health as well. Furthermore, a review of the previous literature in such a field shows a lack of study regarding the situation of Roma women in their access to reproductive health services. Taking into consideration the reasons mentioned above, this paper aims to serve as an orientation for the course of the State \& Community Policies in such a field. The paper is focused in three main aspects: analysis of the Albanian normative framework in regard to reproductive health, situation of Roma women regarding their access in reproductive health services and drawing conclusions regarding the equal treatment of Roma women in the field of reproductive health.
\end{abstract}

Keywords: Roma women, discrimination, reproductive health

\section{Introduction}

Reproductive health is a very important part of general health, constituting a central feature of the human development. As a universal concept, the reproductive health is of special importance for women, especially during their reproductive years. Due to the importance of such a concept for the general health, it can be considered as a pre-condition for the economic social and human development. ${ }^{1}$

At a world level, the International Conference on Population and Development (ICDP), held in Cairo, in 1994, was the first conference that accepted the development of a Programme of Action to address the reproductive health. Before these years, the notion of reproductive health was almost unknown, due to the state policies orientated towards the demographic growth of the population. The approach to the reproductive health services approved by ICDP was based on the views regarding the estimation of women and on the concern for their health and prosperity. Furthermore, the reproductive health capacity was transformed from a means of population control into an issue of strengthening women to exercise their personal autonomy in relation to their sexual and reproductive health within their sexual, economic and cultural context ${ }^{2}$. The concept "reproductive health" was defined in paragraph 7.2 of the Programme of Action (ICDP,1994) as "a state of complete physical, mental and social wellbeing in all matters relating to the reproductive health system" Reproductive health therefore "implies that people are able to have a satisfying and safe sex life and that they have the capacity to reproduce and the freedom to decide if, when and how often to do so". ${ }^{3}$

\footnotetext{
${ }^{1}$ For further information see: United Nations "Guidelines on reproductive health" in its online format at http://www.un.org/popin/unfpa/taskforce/guide/iatfreph.gdl.html referred on 15.10.2015.

${ }^{2}$ Carmel Shalev "Rights to Sexual and Reproductive Health - the ICPD and the Convention on the Elimination of All Forms of

Discrimination Against Women", article presented in the International Conference on Reproductive Health, Mumbai (India), 15-19 March 1998, jointly organised by the Indian Society for the Study of Reproduction and Fertility and the UNDP/UNFPA/WHO/World Bank Special Programme of Research, Development and Research Training in Human Reproduction tek http://www.un.org/womenwatch/daw/csw/shalev.htm
}

3 lbid. 
At the same time, in Albania, the concept of family planning and modern contraception before the ' 90 -ties was a taboo, due to strictly followed pro-natal policies during the time of mono-party system. Modern contraceptive methods were almost unknown for the wide population, while in pharmacies could be found only a limited number (mainly of condoms) which were given only in special cases. ${ }^{1}$ Abortion was considered illegal. Abortion was considered as a criminal offence and the women who aborted were stigmatized and prejudiced by the society².

After the '90-ties, with the change of the political system, Albania started to embrace the concepts of family planning, the modern contraception, the reproductive and sexual health, by formatting and completing the legal framework of the reproductive health. ${ }^{3}$ From this moment and on, the right to benefit from the health services, in general and from the reproductive health services in particular, is considered to be part of the fundamental human rights. The law "On the health care in the Republic of Albania" defines and guarantees equal rights in the health care services, based upon nondiscrimination, and is considered as a fundamental principle. The setting up of the health care service is based upon the efficiency and the quality of the service by guaranteeing the safety of the patient and impartiality. Being fair in the treatment means offering the health care services taking into consideration all the different needs that the individuals have, aiming at setting up an adequate system and sensitive from the gender point of view. Equal treatment and non-discrimination of Roma women in relation to their access to the reproductive health services is part of the obligations of the Albanian State in compliance with the international standards.

From a methodological point of view, the compiling of this paper and identification of accurate findings, are based upon the combination of qualitative and quantitative methods. The review of the existing legislation and of the existing literature, related to the issue, has been the main source regarding the theoretical point of view. Meanwhile, in order to reflect the concrete situation of Roma women regarding their access to reproductive services, the paper is based on the questionnaires prepared by the author for this aim. The report is based as well on the direct interviews performed by the author with Roma women. In order to set up a trust relationship with Roma women, the filling in of the questionnaires and interviews were realized with the intermediation of experts belonging to Roma community, or with the intermediation of the organizations defending the Roma women rights. There were interviewed 70 Roma women of the age group from 16 to 60 years old and were organised 4 meetings with 8 roma women each one. Delivery of questionnaires was extended in some cities of Albania, such as in Korça, Pogradec and Tirana, where the concentration of such a population is higher than in other cities/towns. Details, gathered findings and data analysis are reflected in the respective parts of the paper. Data analysis is based on the principles of participation in a study/survey by not using in any case personally identified information.

\section{National legal standards in the field of reproductive health}

The constitution of the Republic of Albania (1998) includes the highest legal standard in guaranteeing of the fundamental rights. In the Constitution of RA, the protection of the health of the mother and of the child constitutes one of the main basic obligations of the state. Article 55 of the Constitution defines that "Citizens enjoy in an equal manner the right to health care from the state." The Constitution defines expressively in article 54 that children, the young, pregnant women and new mothers have the right to special protection by the state.

Also, the Albanian legislation in the field of protection of equality and non-discrimination guarantees equal access in public services, including reproductive health services despite the race or the ethnic origin. This means that the Albanian state has the positive obligation to guarantee the full access of Roma women in all the components of the services in the field of reproductive health.

Law "On protection from discrimination" regulates the implementation and the respecting of the equality principle in relation to a number of unlimited reasons including inter alia the race and the ethnic origin. The aim of this law is to ensure the right of each person (including Roma women) to be treated equally under the law, to have equal possibilities and opportunities

\footnotetext{
${ }^{1}$ ACPD and UNFPA "Alternative Report of NGO-s on the situation in the country related to the reproductive health components", pg 6.

2 Gjonça, A., Aassve, A., and Mencarini, L. 2009, "The highest fertility in Europe-for how long?" Determinants of fertility change in

Albania, Demography 52(5):76-96 [English edition].

${ }^{3}$ See above, Ref.4.
} 
to exercise their rights (understand "in the field of the reproductive health") as well as an effective protection from discrimination due to the ethnic origin. ${ }^{1}$

Article 20 of this law ensures protection against discrimination in the field of goods and services. In a specific way the right to profit from the services having to do with the health (including reproductive health as well) is guaranteed in letter (b) of the second paragraph of article 20. For the aim of this paper, discrimination of Roma women regarding their benefit and access to the reproductive health services implies that the physic individual and/or the legal entity that offers goods or services in relation to reproductive health, whether or not with payment:

refuses to offer a woman goods or services due to her Roma origin;

Refuses to offer a Roma woman goods or services in a similar manner, or with similar qualities, or in conditions similar to that in which those goods or services are offered to others. ${ }^{2}$

Guaranteeing a high health care, either physical or mental is part of the social objectives of the Albanian State (Article 59/1 (c)). Nevertheless, in the Constitution text is identified the lack of special provisions protecting the reproductive rights. Based on this identification, it is necessary to refer to specific laws that regulate the field of reproductive health: Law no.8045, dated 07.12.1995 "On termination of pregnancy" and Law no.8876, dated 4.4.2002, "On reproductive health".

According to the law "On reproductive health" the term "reproductive health" means general physical and mental well-being, as a whole, with the absence of problematic incapacities and illnesses, as well as every other basic conditioning provision that the reproductive system needs for the functions, processes and ability for a satisfactory and safe sexual life. It means the ability of people to reproduce and their freedom to choose the manner and time of reproduction, as well as to be informed of where they can do this and where they can find such services. ${ }^{3}$

Article 3 of this law defines that the reproductive health care includes an entirety of methods, techniques and health services that affect the reproductive health of people, preventing and solving their problems, as below:

The right of Roma women to benefit services counseling and information on family planning.

Law "On reproductive health" foresees that "Every woman, free and excluded from any form of discrimination, obligation or force, has the right to control and freely to decide about all questions related to her sexuality and her sexual and reproductive health." The law sanctions the right of each individual to decide freely, but by respecting the desire of each partner, regarding the time, the number of births and the intervals of birth giving, to get informed for the necessary means of realizing and to request for the highest standards of the reproductive and sexual health. From this point of view, the Law "On reproductive health" guarantees to each individual the decision-making to exercise the reproductive rights according to their interests and desire, free from discrimination, obligation and violence. ${ }^{4}$ This freedom in decision-making implies that no woman could be forced to be pregnant and every medical intervention related to the reproductive health should be realized with the free consent of the person upon whom the medical intervention will happen. ${ }^{5}$

Women's right for information is defined as well in the law "On Termination of pregnancy". Article 2 of this law sanctions that the woman has the right of accurate information and counseling before termination of pregnancy. Counseling and information regarding the family planning service after the termination of pregnancy is considered as an immediate issue to avoid the unwanted pregnancies.

Also, an important role should be played by planning \& counseling clinics for women. According to the law, such clinics should give the women who have requested to terminate the pregnancy, the proper information and counseling. The law allows termination of pregnancy only with the consent of the woman. Nevertheless the law defines that when it is possible, in counseling and in decision taking for the termination of pregnancy can participate the husband as well. In cases of

\footnotetext{
${ }^{1}$ Article 2 of the law No. 10221, dated on 4.2.2010 "On protection from discrimination"

${ }^{2}$ Article 20/1 of the law "No. 10221, dated 4.2.2010 "On protection from discrimination"

3 See definition of "reproductive health" in article 2 of the law no.8876, dated 4.4.2002, "On reproductive health"

${ }^{4}$ Article 8 of the law no.8876, dated 4.4.2002, "On reproductive health"

${ }^{5}$ Article 9 of the law no.8876, dated 4.4 .2002 , "On reproductive health"
} 
voluntary termination of pregnancy the right for information implies the obligation of the doctor to inform the woman in relation to:

Medical risks/threats deriving from termination of pregnancy

The rights, the assistance and the guaranteed advantaged in relation to the family, the mother and the child

Institutions and bodies that can offer moral \& financial support to the woman

\section{Clinics and hospitals who realize the termination of pregnancy. ${ }^{1}$}

If the woman repeats her request for termination of pregnancy after getting the information, the doctor asks for a written consent from the woman. The confirmation should be given within 7 days from the first request. In cases that there is a minor girl up to 16 years old, the law foresees that for the termination of the pregnancy it isn't necessary to get only the request and the consent from the girl. In such cases, is necessary to be deposited the consent of the parents or of the legal guardian of the girl'2.

Law "On termination of pregnancy" foresees that the woman may ask for the termination of pregnancy with her own will, within the $12^{\text {th }}$ week of pregnancy, if she judges that pregnancy creates psychological problems to her ${ }^{3}$ and up to the $22^{\text {nd }}$ week of pregnancy in case of identification of medical problems. Termination of pregnancy is allowed for social reasons, within the $22^{\text {nd }}$ week, in case that a commission composed of 3 specialists assess that pregnancy has come as a result of rape, or as a result of any other sexual crime, as well as in cases when there are certified other social reasons. ${ }^{4}$

\section{The right of women to benefit from the services of prenatal care, safe delivery and postnatal care.}

Law "On reproductive health" guarantees the right of women for a safe motherhood. According to this law, each woman should take the necessary care in order to have good health from pregnancy up to giving birth to the child. In this point of view, each woman should have access in all the services offered, with a high quality, before delivery, during and after delivery, for the prevention of unwanted pregnancy, prevention of unsafe abortion and premature delivery. In this context, family planning services should be used and promoted to protect the woman health and to avoid the unwanted pregnancy. General checks before delivery is allowed for all the women . ${ }^{5}$ Provision of health protection during pregnancy and the assistance during delivery are necessary to minimize the risk for the health of the woman, of the fetus, of the newborn, or of the child.

The right of women to information and to benefit from services on sexuality and on reproductive health.

Law "On reproductive health" guarantees the right of each individual to be informed, advised, to get the education and the necessary health and social service to enjoy good sexual health, as well as to exercise their reproductive and sexual rights. ${ }^{6}$ Every woman has the right to freely control her reproductive life, as well as to benefit from the use of safe methods, which should be affordable and acceptable for the family planning. Before using such methods, every woman should take the proper information regarding the risks and the advantages of each method including the use of condoms, vaginal barrier methods, oral contraceptives, implants, injection methods, IUD, voluntary male and female sterilization and the emergency contraception. ${ }^{7}$

The right of women for safe services, affordable and acceptable in the field of the reproductive health ${ }^{8}$

\footnotetext{
${ }^{1}$ Article 4 of the law no. 8045 , dated 07.12 .1995 "On termination of pregnancy".

2 Article 8 of the law no. 8045, dated 07.12.1995 "On termination of pregnancy".

${ }^{3}$ Article 10 of the law no. 8045, dated 07.12 .1995 "On termination of pregnancy".

${ }^{4}$ Article 11 of the law no. 8045, datë 07.12 .1995 "On termination of pregnancy".

${ }^{5}$ Article 27 of the law no.8876, dated 4.4.2002, "On reproductive health"

${ }^{6}$ Article 5 of the law no.8876, dated 4.4.2002, "On reproduction health".

${ }^{7}$ See article 26 of the law no.8876, dated 4.4.2002, "On reproduction health"

${ }^{8}$ Article 10 of the law no.8876, dated 4.4.2002, "On reproduction health"
} 
Law "On reproductive health" foresees the right of all individuals for useful, acceptable, accessible and qualitative services in the field of reproductive health". According to this law "All individuals have the right to benefit from scientific progress and new technologies related to reproduction and sexuality, when they are safe and acceptable.". ${ }^{2}$ The health services in the field of the reproductive health should be easily achievable from Roma women, in order to enable them to have possibilities to benefit from them aiming at the protection of their sexual and reproductive health. The legislation defines that all pregnant women enjoy for free the periodic medical following of their pregnancy, the birth and after the birth, especially obligatory pre-natal and post-natal examinations, which are designated by act of the Minister of Health. ${ }^{3}$ The obligatory examinations prescribed by the doctor are offered without payment and every woman has the right to have for free her personal journal on the progress of the pregnancy. It is important that the health services should have a special individual character, which means that they should be offered for every woman by taking into consideration the health situation, the age and the individual characteristics.

Certain services of the reproductive health can help women treat their infertility. For this aim, the law "On reproductive health" defines their right to benefit from the application of the modern technological methods for the reproduction after taking the necessary information on the contents of the supplementary reproductive technologies, on their efficiency, on the optimal periods for their application, on the medical consequences and on the potential side effects, as well as on the information on the validity of other methods on treating the infertility. ${ }^{4}$

\section{Protection of breastfeeding}

In 1999, the Assembly of the Republic of Albania approved a law on the protection of breastfeeding ${ }^{5}$. More than defining the rules for the protection of breastfeeding, this law defines the rules of trading the alternative products of the child's food. Previous surveys in this field have considered the law "On promotion and protection of breastfeeding" as a law drafted only to discourage the substitution of breast milk with the artificial one, in order to define rules in trading the products for little children and to spread the information regarding the advantages of the breastfeeding. Based on this in the evaluation report of CEDAW for Albania (2005), it is highlighted that the protection dedicated by the Albanian legislation to breastfeeding is limited and provisions or programs to provide the proper food for the new mothers lack in general. ${ }^{6}$

The law defines the obligation of the directors of the health centers and of the health authorities, either local or national ones, to promote, to support and to protect breastfeeding and to make public the problems created by the alternative feeding. Nevertheless, the law contains few and insufficient provisions to promote and to guarantee breastfeeding of the child. The law doesn't foresee measures to support the mother for the breastfeeding of the child with her natural milk. ${ }^{7}$

\section{3: Discrimination of Roma women regarding their access in the reproductive health}

Roma community composes one of the cultural and language minorities in Albania having many problems regarding their economic situation and the regarding the barriers they have to face during their everyday life. There is a lack of official statistics related to the number of Roma population in Albania. So, this paper will refer to the statistics given by the studies performed by the Roma organizations in Albania and by independent institutions. Their statistics give a number of the population that varies from 90 to 120 thousand and most of them live in urbane zones and in the suburbs of the cities ${ }^{8}$. At the same time, these studies have highlighted that the growth of Roma population is $3 \%$, by over passing the percentage of the growth of the Albanian population. ${ }^{9}$ This paper, even though it doesn't cover all Roma community, through the analysis of the personal experiences of Roma women, highlights that Roma women have lower access to the services offered in the field of the reproductive health and in the field of family planning than the other part of the women. Their health situation is worse compared with the other part of the population. This is influenced by the economic situation of

\footnotetext{
${ }^{1}$ Anastas.A "Women's rights in the Albanian legislation", Information booklet, OSCE-Presence in Albania, 2010

${ }^{2}$ Article $10 / 3$ of the law no.8876, dated 4.4.2002, "On reproductive health"

${ }^{3}$ Article 24 of the law no.8876, dated 4.4.2002, "On reproductive health"

${ }^{4}$ Article 20 of the law no.8876, dated 4.4.2002, "On reproductive health"

5 Law No. 8528, dated. 23.9. 1999, "Promotion and protection of breastfeeding"

${ }^{6}$ See USAID "Report on evaluation of implementation of the Convention on Elimination of all Forms of Discrimination Against Women, in Albania, December 2005, page 47.

${ }^{7}$ Anastas.A "The rights of women in the Albanian Legislation", informative booklet, OSCE Presence in Albania, 2010, page 38.

8 For more see "The decade of Roma inclusion 2012-2015", page 6.

9 lbid.
} 
Roma women and by the style of their life. In order for this paper to be of as much help as possible to the Roma community, based upon the questionnaires and upon the interviews performed with Roma women, it will offer, in this part of it, an analysis of the scope of discrimination towards Roma women in the field of the reproductive health. It will identify some of the most frequent practices of discrimination towards Roma women in two main directions: firstly, under the framework of the differentiated treatment of Roma women from the providers of the reproductive health services and secondly considering such a treatment from the point of view of Roma women access in reproductive health services and the existing institutional barriers.

The differentiated treatment:

In general terms the differentiated treatment of Roma women during the provision of the reproductive health services includes: scornful treatment, superficial treatment, verbal abuse, providing separated services, delayed care, refusal of care provision from the doctors, etc. In order to make better known the practices of differentiated treatment the following part of the paper is focused upon the treatment of concrete situations which are evidenced in different cases. The differentiated treatment from the provider of the services especially from the medical personnel in many cases goes against the rules of ethics norming the relations between the medical personnel and the patient. It is clearly set that such relations are not affected by the ethnic origin of the patient in any case. The key issues identified in relation to such a treatment are as follows:

\section{Refusal of the specialized medical personnel to offer services to Roma women:}

In general, refusal apply by the respective medical personnel who are obliged to offer the health service required by Roma women. The reasons of the differentiated treatment may be different. Such reasons may be related either to the ethnic origin or to lack of offering money from Roma women. So in some cases, the medical personnel refuse to offer the proper treatment to Roma women based on the fact that Roma women are poor and as a consequence they are not going to pay them. Request for informal payment is considered as the reason of not offering the medical services and the medical care to the majority of the women included in the survey. $68 \%$ of the interviewed women reported that the doctors have requested money to assist in the moments of child birth. In their interviews Roma women have stated: "I was about to give birth to my child. No one approached me. The doctors requested money. I felt abandoned"(M.M 30 years old)."I remember that no one cared to bring my child to me. Such a situation continued to happen till the moment that my husband offered money to them. I don't know where he found that sum of money, because we didn't have any possibility"( G.M 27 years old) "The doctors have treated me normally...but I paid money to them"(E.T 45 years old).

The informal payment as a discriminatory criterion is identified even in previous studies focused on Roma population. So in an evaluation of the situation of Roma population in 2011 has resulted that "Almost $83 \%$ of the interviewed individuals of Roma community pay bribes for health services in the public health centers and in public hospitals. Informal payments and other corruptive forms of payment bring about the increase of the costs for the health services, improper health treatment and health deterioration." In other cases, the differentiated treatment was simulated by ethnic factors. In such situations the doctors refuse to provide services of reproductive health to Roma women due to their origin. "The doctors do not want to provide medical checks for us because we come from Roma community. They mock on us. They say: you have a lot of children"(E.H 25 years old). "I was waiting in the corridor to be medically checked. I heard two nurses talking to each other [One of them said "I can't stand Roma community. Their women are always pregnant. This one here (speaking for me) is not more than 15. ]" (S.H 21 years old).

\subsubsection{Providing reproductive health services not with the same quality}

Another practice of differentiated training is providing reproductive health services not with the same quality as it is offered to women who do not belong to Roma community. It is worth emphasizing as cases of differentiated practices such as providing superficial medical check, within e very short time, or delaying for a long time the provision of necessary services to Roma women. "Nurses were indifferent towards me. They didn't treat me the same with the others" (M.M 20 years old) "The doctors were not careful at all with me. The doctors didn't provide me a proper medical care. After I gave birth to my child I had infection" (G.M 40 years old). Besides the superficial treatment, another identified situation among

\footnotetext{
1 See Center for Economic and Social Studies (CESS)" Study on evaluation of the needs of Roma and Egyptian communities in Albania", Tirana, 29 February 2012, page 33.
} 
Roma women is the delay of the service (Roma women are left to wait for long periods of time). According to them, the doctors wanted to finish all their visits with non-Roma women and then, if the doctor had time he/she may offer medical checks for Roma women. M.M tells that "When I want to give birth to my child, I was told to wait, because there were other patients. I could hardly stand". M.R speaks of a similar situation: "When I went to the doctor for a sonography, I was left to wait. All the other cases finished before me".

\subsubsection{Inferior treatment of Roma women from the specialized medical personnel:}

Inferior cases are related to all those cases when Roma women "are maltreated" by the medical personnel through verbal abuse, insults based on their ethnic origin, or there are cases of benefiting from reproductive health services under conditions that are not the same as the conditions under which the patients coming from non-Roma origin profit such services. Roma women tell the doctors mock on them. Sometimes they offend them or they keep away from Roma women "due to their lack of cleanness", due to "high number of children", or due to "frequency of pregnancy".

\subsection{Lack of access of Roma women regarding the reproductive health services}

Based on an assessment of Roma women situation regarding their access to reproductive health services it results that Roma women face with a lot of barriers in order to have such services. It is important to make known such barriers, in order to lead the Albanian policymakers towards strategies and Plans of Action that address directly the removal of such barriers, or at least guarantee a gradual minimization of them. On the other side, the existence of barriers, especially the existence of institutional barriers regarding the access of Roma women in benefiting from reproductive health services, may bring about either a direct, or an indirect discrimination referring to the consequences coming as a result of not taking measures to eliminate such barriers. Lack of access due to barriers produces "exclusion from the provision of services in such a field due to the ethnic origin from Roma community". Such barriers may be divided into four main categories, which are as follows: information barriers, geographical barriers, economic barriers and institutional ones.

\subsubsection{Lack of information regarding the components of the reproductive health}

Regarding the information barriers, it is identified that the majority of Roma women do not have any access to information on the provided services under the framework of family planning, on the concepts of reproductive system and on the components of the reproductive health. Roma women were asked in relation to their sources of information on such services. Almost $70 \%$ of them mentioned as their source of information their mother/ their sister/ TV. $20 \%$ of them defined as a source of information the teachers at school, while $10 \%$ of the participants in the study mentioned as a source of information the school texts (biology). It is worth emphasizing the fact that none of the interviewees mentioned the doctors as a source of information on the components of the reproductive health services and of the family planning.

Roma women didn't have information regarding the methods used to avoid the unwanted pregnancy. Roma women had lack of access in information in relation to the contraceptive methods in favor of family planning and in avoidance of unwanted pregnancy. They also lacked information relating to their use. In a lot of cases, the women emphasized the fact that they were not interested in the usage of such methods, because they cost money. According to the interviewees, the abortion is the main method used to terminate the pregnancy. To make an abortion or not is not decided by Roma woman herself, but it is a decision taken by other members of the family. The decision is taken usually by her husband, by her mother in law, or by her parents.

Some of the interviewees reported that in the health centers where they have gone there have been some informative booklets related to such issues, but some of them said as follows: "I do not understand booklets given to me, because I do not know how to read. I do not understand doctors as well when they speak." (E.H 36 years old) "It has never been organized any training with us. We should be gathered and the doctors should explain to us such issues. We can not understand such things by ourselves." (A.K 25 years old). The access to information is related as well to the low access of Roma women to institutions of providing education services. Lacking the necessary education, it is very difficult for Roma women to understand and to absorb the proper information given sometimes even through the TV transmissions as a source of information. Based on what is described above it is very much important to take measures to ensure raising of Roma women access to the information on the understanding and on the functioning of the kinds, on the manners and on the cases of using the available methods on family planning and on the avoidance of unwanted pregnancy.

\subsubsection{Lack of documents.}


Another barrier hindering Roma women regarding their access in such services is lack of proper documents to benefit from the services. Reproductive health services are provided only to the women who are in possession of a Health Card. Roma women who are not issued with a Health Card can lose their access to the institutions who offer such services. Among the interviewed Roma women there was a part of them who were not registered, who didn't have the identity card, who were not employed, or who did informal work (didn't have any regular employment contract), who haven't registered their children, who didn't have birth certificates, etc. Each of the documents mentioned above may be a condition to be fulfilled in order to benefit from the public health insurances. Being not insured, Roma women do not have access even in the services provided by the reproductive health. One of Roma women said:" I was told that if you don't have a Health Card you would profit nothing free of charge. Per each check up you are going to do, you are going to pay". Roma women relate the reasons and the obstacles to be issued with the necessary documents with the institutional barriers. They were asked on the reasons of not been issued with the Health Cards. Some of them answered: "There are needed a lot of documents. You have to wait a lot of time to get the Health Card". One of the activists who protects the rights of Roma women told as follows: "Roma girls face difficulties in being provided with Health Cards. We have assisted a case. G.M was only 14 years old. She got married with a boy who was 18 years old and she immediately remained pregnant. She couldn't go to the doctor to check whether her child was growing up normally, or just to know the sex of her child, because she didn't have a Health Card, so no one took care of her. We assisted her to issue her Health Card. So only in her last month of pregnancy she could have the first sonography of her child." The same activist in relation to the difficulties of providing Roma women and girls with the Health Cards highlighted: "we have encountered a lot of difficulties in different institutions. It has been so difficult to obtain Health Cards for Roma women and girls due to the set of documents needed. Roma women and girls didn't have such documents. So I had to go in different institutions to get these documents. We had to spend months in order to obtain a Health Card. Not all the doors of the institutions are opened for them." On what is described above the respective state institutions not only shouldn't become an obstacle themselves in issuing health Cards for Roma women, but they have to take the necessary measures to raise the institutional cooperation in order to ensure Roma women all the opportunities and not to wander from one institution to the other to gather the necessary documents. The institutions should facilitate the procedures to issue Health Cards for Roma women. On the other side it is considered necessary holding of informing session for Roma women and girls in relation to the necessity of registration and of being issued with the personal Health Card. They should be informed as well regarding the necessary documents needed to get registered and on the benefits deriving as a result of being registered in the respective institutions.

\subsubsection{Physical/geographical barriers}

Regarding the physical/geographical barriers, monitoring of discriminatory practices towards Roma women has proved that lack of health care centers/ care centers for women in the area of living of Roma population is one of the cases of discrimination towards such a population. The majority of roma women reported that there wasn't any health care centers set up near the areas where they live. In order to consult the doctor or to have certain check ups they have to travel a lot.

Roma population usually is settled in the suburbs of the cities, so their living area is away from service providers. Such a distance limits the access of Roma women to reproductive health care services. The transport costs sometimes are very expensive for them. Such a situation brings as a result lack of access of Roma women to the doctors during the whole period of before and after giving birth to their child. Lack of centers near their locations cause a lot of problems for them. Even when Roma women have got information in relation to family planning, their access in the provided services in these centers become impossible due to the distance and due to transport costs. So, as a result, such barriers may oblige Roma women to apply the "domestic" forms and to try the informal "clinics" in cases of abortions. Such a form of discrimination becomes stronger with Roma women and girls who live in rural areas, or in isolated areas.

Physical barriers to the access of Roma women in the centers where such services are provided come as well as a result of frequent displacement of such a community from one area to the other, from one village/city to the other. As a rule such a displacement should be followed by the transfer of the respective documents as well, in order to deregister the Roma population from one public health center and to register them in the public health center in the area where they are displaced. During the interviews realized with Roma women, some of them considered the transfer of documents from one health center to the other as irrelevant due to lack of access in such centers, due to informal payment, due to long time spent for the procedures, etc. 
Under such conditions, should be taken measures to ensure an equal access in the centers providing reproductive health care services for all Roma women and girls despite the area where they come from. New health care centers should be set up in order to offer an equal service to all categories of the population.

\subsubsection{Lack of cultural intermediators}

Lack of cultural intermediators is another barrier that hinders the access of Roma women to the institutions and centers that offer reproductive health services, especially for those Roma women who do not speak and understand the Albanian language. Almost all the previous surveys performed in relation to the peculiarities of Roma population have come to the conclusion that they are a language minority. This finding implies the fact that Roma population speaks its own language. Even that Roma women live in Albania, a part of them doesn't speak the Albanian language. Lack of language knowledge is one of the reasons of their discrimination, because due to lack of communication in the Albanian language they lose the provided health care services. Roma women were asked whether their limited knowledge in the written and spoken Albanian language has been a barrier in getting the full and clear information in relation to the services in general and to the reproductive health services in particular. They were also asked whether the limited knowledge in Albanian language has created problems in getting such services. Roma women answered as follows: "It is very difficult for me to explain to the doctor my own health problems during the pregnancy, because I do not understand the language they use". "Yes, it is a barrier. I don't know how to read and write" ( A.K 30 years old). "It is difficult for me; I do not understand the doctors when they speak. I do not understand what they tell me to do" (E.Zh). Based on the situations described above and taking into consideration the low access of this community in the educational institutions, it is necessary to have the presence of the cultural intermediators coming from this community and employed by the institutions that offer reproductive health services.

\section{Conclusions}

Equal treatment and non-discrimination of Roma women regarding their access to the reproductive health services are part of the obligations undertaken by the Albanian State to implement the International Rights in such a field. Acknowledgement of the equal rights of Roma women and setting up a proper environment to fully implement their rights is as well part of the challenges that the Albanian policymakers and lawmakers have to face and address during all the period of Roma decade (2010-2015).

This paper identified that Roma women in a way or in another, are excluded from the possibility of applying into practice, in an equal and full way, their reproductive rights. Their access to the reproductive health services is hindered from the existence of a lot of barriers of the economic, geographical, informative and institutional character. The differentiated treatment offered to this ethnic category of the population and the lack of equal access are in themselves forms of direct and indirect discrimination of the public or private providers of services in such a field.

The doctors refuse to offer services to Roma women in the field of reproductive health for two main reasons: Roma women are in a very difficult economic situation, so usually they do not have possibilities to pay for the doctor (in an informal way), in order to profit the service. The second reason is related mostly to their ethnic origin. The doctors hinder the access of Roma women in the services provided in this field. Fight against corruption remains one of the most important challenges that the Albanian health service is facing with.

Roma women have to wait for a longer time as compared to other women coming from a non-Roma origin for the same provided services. They face lack of access in some cases. They face as well with the prejudices and with the insults regarding the high number of children they have and regarding their personal hygiene. In their relations with Roma women medical personnel do not respect the principles of the Code of Ethics that defines the relations of the doctor with his patients. On the contrary, there are cases of prejudices in the doctors' behavior towards such an ethnic category of the population and such prejudices are turned into racial discrimination.

Week infrastructure and the geographical barriers bring about another problem that influences in the discrimination of Roma women regarding the provision of reproductive health services. Consulting centers for women and the health care centers in most of the cases are less accessible or sometimes not at all accessible for Roma women due to the large distance of the centers from Roma population areas of living. The transportation costs are not affordable for this category of the population. Such a distance brings as a result that Roma women suffer from a lot of health problems during their period of 
pregnancy, because they can not have access to continuous and periodic medical checks, either in the period before giving birth to their children, or in the period after they have given birth to their children.

A part of Roma women do not have access in public services offered in the field of the reproductive health, due to lack of necessary documents. Other identified problems are lack of information and low level of awareness raising among Roma women regarding the components of the reproductive health and family planning. The reasons that influence in lack of information are as follows: low educational level of Roma women, difficulties in understanding the Albanian language, lack of training in relation to family planning and to use of contraceptive methods to avoid the unwanted pregnancy etc. Due to low awareness and due to lack of information, abortion remains for the majority of Roma women the best and the most practical solution in cases of an unwanted pregnancy.

Lack of cultural intermediators is another barrier hindering Roma women access to institutions and centers that offer reproductive health services, especially for those women who do not understand the Albanian language. Low awareness level of Roma women has brought about lack of treatment of their cases in the specialized bodies/institutions that protect the equal treatment (such as the institution of the Commissioner for the Protection from Discrimination). Roma women have very little information, or they do not have information at all regarding the available legal instruments in the Albanian legislation to condemn the cases of racial discrimination in the field of provision of services. The law "On protection from discrimination" is accessible in Roma language, but still it is not known by the majority of Roma women. Lack of information is related not only to the treatment of discrimination cases, but it is related as well to the scope of rights that they enjoy by the Albanian law in the field of reproductive health. 